\title{
THE EFFECT OF MECHANICAL VIBRATION ON THE GASEOUS EXCHANGE AND LUNG FUNCTIONS OF PATIENTS WITH ACUTE
}

\section{LUNG INJURY}

\author{
by S P Wessels \\ $M S c$ Physiotherapy \\ University of Stellenbosch
}

\section{INTRODUCTION}

The use of chest physiotherapy is a well-established primary and supplemental treatment of patients with a variety of respiratory diseases. The purpose of the intervention is improvement of mucocilliary clearing, increased sputum production, bronchodilatation and improvement of gaseous exchange.

Respiratory physiotherapy techniques may be divided into two categories. The first, "pulmonary physiotherapy", includes techniques designed to reduce airway resistance, to improve intrapulmonary gaseous exchange and to reduce complications like atelectasis and pneumonia. This group consists of postural drainage, chest percussion, vibration and stimulation of cough. The second category, "breathing exercises", includes techniques to relieve dyspnoea, to improve ventilation effectiveness and to improve exercise capacity.

\section{Mechanical and Manual Vibration}

There is a tendency in the literature for authors not to differentiate between manual and mechanical vibration and chest shaking. For this reason, some regard rib fractures (the pathology in this study) as a contra-indication for vibration (Mackenzie 1989). Manual vibration is a gentle technique with a high frequency and small amplitude whereas chest shaking is a more forceful technique with a lower frequency and greater amplitude.

True manual vibration is not as widely used in clinical practice as some people assume because of the fact that it is a difficult and tiresome technique. Mechanical vibration that also produces a high frequency and small amplitude is an appropriate alternative and, therefore, it was applied in this research.

The main reason for the study was to determine the effect of one specific technique (mechanical vibration) on gaseous exchange and lung functions in patients with acute blunt chest trauma.

\section{Effect of Chest Physiotherapy on Acute Lung Conditions}

Chest physiotherapy for patients with chronic airway diseases has been studied with varying results $1,2,3,6,15,16,18$.

There is little published data concerning the effectiveness of chest physiotherapy in the treatment of patients with acute lung injury. Mackenzie et al (1979) investigated the effects of postural drainage, percussion/manual vibration and cough stimulation/suctioning on oxygenation and chest X-rays (CXR) in mechanically ventilated patients. Improvement in chest X-rays and no change in $\mathrm{PaO}_{2}$ was shown. Conners et al (1980) studied the immediate effect of postural drainage and percussion on oxygenation in patients with acute pulmonary disorders. The study demonstrated a significant decrease in the $\mathrm{PaO}_{2}$ after treatment in the patients that produced very little sputum and no change in $\mathrm{PaO}_{2}$ in the patients who produced moderate amounts of sputum. Marini et al (1979) studied the effect of breathing exercises/bagging, coughing/suctioning, inhalation, percussion and postural drainage on spontaneous breathing/mechanically ventilated patients with consolidation/atelectasis. Holody and Goldberg (1980) studied the effect of mechanical vibration on arterial oxygenation in acutely ill mechanically ventilated patients with atelectasis or pneumonia. The results showed a significant improvement in the $\mathrm{PaO}_{2}$ and $\mathrm{pH}$.

\section{PATHOPHYSIOLOGICAL BACKGROUND}

Most injuries of the chest cause damage to the underlying lung leading to both underventilation and ventilation-perfusion disturbances in the lung. The reduction in alveolar ventilation is due to five factors:

- instability of the chest wall

- pleural effusion or pneumothorax

- reduction in compliance caused by contusion

- atelectasis

\section{SUMMARY}

In this study, the effect of mechanical vibration, on the gaseous exchange and lung functions of patients with acute lung injury was evaluated. The use of combinations of techniques in previous studies and, the failure to contribute success or failure to any one treatment modality, was the main motivation for this study.

A study was done in which the experimental group received mechanical vibration and the control group only routine respiratory care. for two treatment sessions. Before, and at various time intervals, after the first and second treatment. blood gases and lung functions were recorded. Chest X-rays (CXR) were taken within 12 hours before the first and within 24 hours after the second treatment. For the ventilation studies, the total group was divided randomly in two groups - in one, ventilation studies were carried out before and after the first treatment and in the other, the studies were carried out before the first and after the second treatment.

There was $s$ significant deterioration in $\mathrm{PaO}_{2}$ two hours after the second treatment, and in $\mathrm{PaO}_{2}$ and $\mathrm{SaO}_{2}$ when the values two hours after the second treatment were compared to the values before the first treatment. The CXR of only two of the patients in the experimental group showed improvement and the others showed either no change or deterioration.

The forced vital capacity (FVC) showed a significant improvement after the first treatment, but no change after the second treatment. The same was seen in the ventilation studies.

- diminution of the respiratory drive because of pain.

Instability of the chest wall is due either to multiple rib fractures, or to fractures of the ribs and the sternum. Unstable sections of the chest wall move paradoxically during spontaneous breathing and waste ventilatory effort. Pneumothorax and haemothorax compress the lung and further depress ventilation. Contusion of the lung and atelectasis reduce lung compliance, the work of breathing in increased, oxygen consumption rises and ventilation is further reduced ${ }^{17}$. 


\section{Treatment of patients with blunt chest trauma (BCT)}

\section{Non-invasive treatment of $\mathrm{BCT}$}

Recovery of lung volumes (FRC) can be achieved with a constant positive airway pressure mask (CPAPM). PEEP as high as $10 \mathrm{~cm}^{2} \mathrm{H}_{2} \mathrm{O}$ can easily be given with a CPAPM. The advantage is that the patient can still cough and can also be ambulated earlier so that complications such as thrombo-embolisms can be minimised. A CPAPM can also be given intermittently. In conjunction with the CPAPM, effective pain relief must be given (van Eeden 1990).

\section{Mechanical Ventilation}

Indications for ventilation after moderate to severe $\mathrm{BCT}$ are:

- associated head injuries with repressed consciousness

- severe facial injuries

- vertebral injury that needs traction

- post-laparotomy or other major surgery

- serious lung contusion

- fractures of the first three ribs (usually associated with severe BCT)

- bilatera: rib fractures with severe paradoxical breathing

- patients with severe BCT ( 8 points) and significant underlying lung disease such as chronic bronchitis and emphysema

\section{Table I: Chest Trauma Index}

\begin{tabular}{|l|l||}
\hline \multicolumn{2}{|c|}{ Severity Index for Blunt Chest Trauma } \\
\hline \multicolumn{1}{|c|}{ Chest Injury } & \multicolumn{1}{c|}{ Value } \\
\hline Rib fractures & 1 point each \\
\hline Costochondral dislocations & 1 point each \\
\hline Sternum/clavicle/scapula fractures & 1 point each \\
\hline Lung contusion & 1 point each side \\
\hline Pneumo/haemothorax & 1 point each side \\
\hline $\begin{array}{l}\text { Significant additional injury } \\
\text { (more than 4 points on the ISS) }\end{array}$ & 1 point each \\
\hline $\begin{array}{l}0-5 \text { mild BCT } \\
5-8 \text { moderate to severe BCT } \\
8-24 \text { severe BCT }\end{array}$ \\
\hline
\end{tabular}

\section{STUDY METHOD}

\section{Choice of Patients}

Fifteen patients with unilateral rib fractures (an example of blunt chest trauma), who were admitted to the Respiratory Critical Care Unit and were treated with a CPAP mask, were studied. Patients excluded were those:

- older than 60 years

- with head injuries

- who had already been hospitalised for more than 72 hours

- who, for some or other reason, could not be turned on the non-fractures side

Patients were randomly divided (using a computer generated pseudo-random number sequence) into experimental and control groups.

\section{Techniques}

In the experimental group, the following physiotherapy techniques were applied:

Mechanical vibration (with a Vibramat at a frequency of 25000 revolutions per minute) over the affected lung areas for $10 \mathrm{~min}$ utes with the patient in side lying on the non-fractured side, and 10 minutes with the patient in supine.

Coughing was encouraged.
The control group of patients were treated using the same method except that mechanical vibration was not applied. The experimental and control groups were treated twice with a 4 hour break in between treatment sessions.

\section{Measurements}

The following changes were noted serially in all subjects:

1. Chest $X$-rays within 12 hours before the first treatment and within 24 hours after the second treatment (AP exposures).

2. Blood analysis was performed on all the patients five minutes before and 30,60 and 120 minutes after the first treatment. Before and after the second treatment blood gases were taken at the same time intervals. The measurements were all done in supine with the bed flat and the patients were in that position for at least 15 minutes prior to data collecting.

3. Spirometry (using the Minato Autospiro) was done at the same time intervals as the blood gases.

The total sample was divided randomly into two groups.

In one group (consisting of eight patients - four from the experimental group and four from the control group) ventilation studies were performed five minuices before the first treatment and 120 minutes after the first treatment.

In the other group (consisting of seven patients - four from the experimental group and three from the control group) the ventilation studies were performed 5 minutes before the first treatment and 120 minutes after the second treatment. For the ventilation studies Krypton and Xenon were used.

\section{RESUI_TS}

\section{Age, Sex and Injuries}

The experimental and control groups were comparable according to the mean age ( 39 years in the experimental and 40.8 years in the control group) and sex (in the experimental group men exceeded the women by $6: 2$ and in the control group by $5: 2$ ).

The two groups were also comparable according to additional injuries

\section{Table II: Additional Injuries}

\begin{tabular}{|c|c|c|}
\hline & Experimental Group & Control Group \\
\hline $\begin{array}{l}\text { Mean number of rib fractures } \\
\text { Mean chest trauma index } \\
\text { Mean injury severity score }\end{array}$ & $\begin{array}{l}6.63 \\
7.63 \\
2.75\end{array}$ & $\begin{array}{l}5.86 \\
7.43 \\
3.00\end{array}$ \\
\hline $\begin{array}{l}\text { Pneumothoraces } \\
\text { Haemothoraces } \\
\text { Lung contusions } \\
\text { Flail chest }\end{array}$ & $\begin{array}{l}3 \\
0 \\
5 \\
1\end{array}$ & $\begin{array}{l}4 \\
5 \\
6 \\
4\end{array}$ \\
\hline
\end{tabular}

Five of the eight patients in the experimental group and four of the seven patients in the control group had a lung infection. Two of the patients in the experimental group produced copious amounts of sputum, five produced moderate amounts of sputum and one had an unproductive cough. Two of the patients in the control group produced copious amounts of sputum, one produced a moderate amount of sputum and four produced little sputum.

In the experimental group four of the eight and in the control group two of the seven patients experienced considerable pain and pain relief (Temgesic) was administrated six-hourly by epidural catheter. In spite of the pain experienced by some, the cooperation of all the patients was very good.

\section{Blood Gases}

In neither the experimental nor the control group did the $\mathrm{PaO}_{2}$, $\mathrm{SaO}_{2}$ or $\mathrm{PaCO}_{2}$ values change significantly at any time interval 
after the first treatment. After the second treatment, in the experimental group there was no significant change in the $\mathrm{PaO}_{2}$ values 30 and 60 minutes after treatment, but at 120 minutes, the $\mathrm{PaO}_{2}$ value deteriorated significantly $(p=0.0481)$ (Fig 1$)$. The values of the $\mathrm{SaO}_{2}$ and $\mathrm{PaCO}_{2}$ did not change significantly at any time interval. When the changes over the two treatments in the experimental group were calculated, a highly significant deterioration in the $\mathrm{PaO}_{2}(p=0.0562)$ and $\mathrm{SaO}_{2}(p=0.0323)$ values were found 120 minutes after the second treatment. Both the $p$-values were significant at the $1 \%$ level according to the exact Wilcoxon test. The $\mathrm{PaCO}_{2}$ values did not change. In the control group, there was no significant change in any of the blood gases at any of the time intervals after the second treatment or when the changes over the two treatments were calculated.

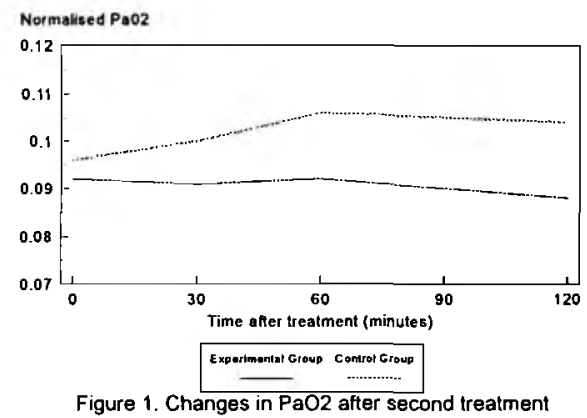

\section{Lung Functions}

In the experimental group, there was no significant change in the forced vital capacity (FVC) value 30 and 120 minutes after the first treatment, but at 60 minutes there was a highly significant improvement $(\mathrm{p}=0.0092)(\mathrm{Fig} 2)$.

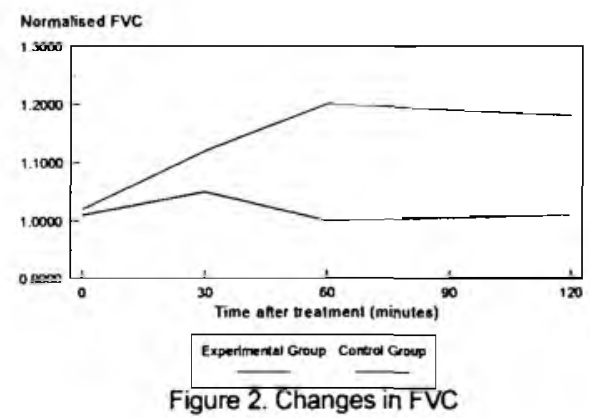

There was no significant change in the forced expiratory volume in one second (FEV1) and peak expiratory flow rate (PEFR) values at any of the time intervals. After the second treatment, there was no change in the FVC, FEV1 and PEFR values at any time interval. There were no significant changes in the lung functions when the changes over the two treatments were calculated and compared.

Calculation of the Trapezoid rule showed a significant $(\mathrm{p}=$ 0.0323 ) improvement in the FVC value after the first treatment (according to the exact Wilcoxon test it is significant at the 5\% level). In the control group, there was no significant change in any of the lung function values at any time interval after the first or second treatment.

\section{Chest X-rays}

In the experimental group two of the Chest $X$-rays (CxR) showed improvement (the patients produced copious amounts of sputum), one showed deterioration (the patient had an unproductive cough) and in five (these patients produced moderate amounts of sputum) no changes were detected. In the control group, the CxR of three patients (two produced copious amounts and one a moderate amount of sputum) showed improvement and four (who produced little sputum) showed no change.

\section{Ventilation Studies}

The ventilation studies which were done before and two hours after the first treatment showed the following results: In the studies of two of the four patients in the experimental group, there were marked improvements. Both these patients produced copious amounts of sputum. One of the studies showed moderate improvement and the patient produced a moderate amount of sputum. The other study showed no change and the patient produced little sputum.

In the control group, the study of one of the patients showed marked improvement and the patient had unproductive cough. One showed marked deterioration and this patient produced a copious amount of sputum. The studies of the other two patients showed no change. Both produced little sputum.

The ventilation studies which were done before the first treatment and two hours after the second treatment showed the following results: In the studies of three of the four patients in the experimental group, there were no changes. The study of the fourth patient had an interesting feature. The patient had four rib fractures on the right side and the second ventilation study showed no change on the right, but a slight reduction in ventilation on the left. All of these patients produced moderate amounts of sputum. In two of the studies of the control group no changes were shown. One of the patients produced a copious amount of sputum and the other one very little.

\section{DISCUSSION}

\section{Blood Gases}

Because of the pain experienced as a result of rib fractures, especially fractures of the 9 th to 11 th ribs, there is a diminished respiratory drive plus impaired ventilation. Progressive alveolar atelectasis follows and this results in a smaller gaseous exchang $\mathrm{e}^{17}$. Lung contusion causes decreased regional alveolar ventilation, because of the blood and fluid in the alveoli, and decreased perfusion to the area of contusion. The decreased perfusion is less than the decreased ventilation due to the loss of the normal pulmonary vasoconstrictory response because of the injury to the capillaries. This leads to $V / Q$ mismatching.

The average number of rib fractures in the experimental group was seven and four of the eight patients had rib fractures below the 9 th rib. Four of the eight patients also experienced a considerable amount of pain. The average number of rib fractures in the control group was six and none of the patients had rib fractures below the 9 th rib. Only two of the seven patients experienced considerable pain. The results of pain are mentioned above and it is clear that the gaseous exchange was the $V / Q$ mismatching that occurred because of the patients' shallow breathing patterns.

According to Mackenzie et al (1978), mechanical ventilation with PEEP plays an important role in the re-expansion of collapsed alveoli, which will lead to improved gaseous exchange and $\mathrm{PaO}_{2}$. The reason for the improvement in $\mathrm{PaO}_{2}$ in Holody and Goldberg's study (1980) and no deterioration in Mackenzie et al study (1978) was probably the mechanical ventilation with PEEP that was used in both studies and not necessarily the mechanical vibration that was applied.

Craven et al (1979) found in their study of right lower lobe contusion in 12 dogs that the contusion produced an average decrease of $20 \mathrm{mmHg}$ in $\mathrm{PaO}_{2}$.

According to Mackenzie et al (1989), lung contusion may improve after chest physiotherapy. The removal of bloody secretions from the areas of normal lung around the contused area, into which bleeding has occurred, may improve the intrapulmonary 
shunt. If the lung is severely contused and lacerated as a result of the injury, no improvement may be seen and there can even be a deterioration in the patient's condition after chest physiotherapy.

The decrease in $\mathrm{PaO}_{2}$ and $\mathrm{SaO}_{2}$ was only significant two hours after the second treatment and although it was statistically significant, it was not clinical significant and none of the patients showed signs of distress.

\section{Lung Functions}

The significant improvement in FVC of the experimental group 60 minutes after the first treatment (Wilcoxon: $p=0.0092$ ) and also after the first treatment as a whole (Trapezoid rule: $p=0.0323$ ) may indicate a decrease in airway resistance. The improvement was the greatest in the two patients who produced copious amounts of sputum.

The forced expiration during the FVC manoeuvre causes higher than normal transpulmonary pressures so that bronchiolar collapse, obstructive lesions, and air trapping are all exaggerated. In this case it did not happen, probably because of the mobilisation and removal of central secretions as a result of the mechanical vibration and coughing.

\section{Chest X-rays}

Mackenzie et al (1978) found in their study an improvement in the CXR of $68 \%$ of the patients in the study group. Marini et al (1979) studied the effect of deep breathing/bagging, coughing/suctioning, inhalation, and percussion and postural drainage for five minutes on patients with acute lobar atelectasis.

The CXR of the patients with central obstruction in the group that received chest physiotherapy demonstrated approximately $37 \%$ restoration of volume loss immediately after the first treatment. Twenty four hours later $80 \%$ of the decreased lung volume was regained.

The CxR of the patients with consolidation/atelectasis demonstrated no significant improvement. According to Marini $e t$ al (1979), respiratory physiotherapy is beneficial in the removal of central secretions, but not in the removal of viscous secretions from the peripheral airways with proximal bronchial obstruction.

Mackenzie et al (1989) sta te that it is still uncertain which component of chest physiotherapy - postural drainage, breathing exercises, percussion, vibration, coughing, or tracheal suctioning - is most effective in clearing secretions from the smaller airways. The exact reason(s) for the improvement in the CXR in the Mackenzie et al (1978) and Marini et al (1979) studies cannot be determined as a number of treatment modalities were used. Kigin
(1981) also reported that when postural drainage and vibration were performed during bronchoscopy, only the secretions in the larger airways became evident.

According to Mackenzie et al (1989), a combination of postural drainage and manoeuvres such as mechanical ventilation with PEEP probably increases the likelihood of re-expansion of non-dependent atelectasis because the uppermost hemithorax is preferentially ventilated.

\section{Ventilation studies}

George et al (1985) studied the changes in mucocilliary clearance during high frequency oscillation at $10 \mathrm{~Hz}(8-12 \mathrm{~Hz})$ in seven non-smokers by monitoring the clearance of inhaled radiolabelled aerosol from the lungs. At three to four and a half hours, the mucocilliary clearance with high frequency oscillation exceeded the control by $10 \%$. The mean time taken to eliminate $90 \%$ of deposited radio-aerosol from the tracheobronchial tree fell from four hours and 50 minutes to three hours 52 minutes during the high frequency oscillation run.

King et al (1983) studied the clearance of mucus in the trachea of nine anaesthetised dogs during high frequency chest wall compressions (HFCWC). The enhancement of clearance during the two minutes of HFCWC was most pronounced in the range of 11 to $15 \mathrm{~Hz}$, reaching a peak value of $340 \%$ at $13 \mathrm{~Hz}$. They discussed several possible mechanisms for this effect. Vibration might reduce the crosslinking that holds the mucus glycoproteins together and facilitate mucus clearance. This possibility is suggested by the fact that the enhancement of clearance sharply peaks in the 11 to $15 \mathrm{~Hz}$ range.

Pavia et al (1976) studied the effect of mechanical vibration at $41 \mathrm{~Hz}$ on the clearance of lung secretions in 10 patients with chronic bronchitis. The removal from the lung of radioactive particles was precisely monitored for five hours by external monitoring. No significant difference was found in the rate of clearance of secretions from the lung when vibration was combined with postural drainage.

The results of the present study suggest that mechanical vibration at $42 \mathrm{~Hz}$ is effective in patients who produced large amounts of sputum as there was marked improvement in ventilation after treatment. In patients who produced small to moderate amounts of sputum, the treatment was ineffective.

The frequencies of 10 and $13 \mathrm{~Hz}$ used by George et al (1985) and King et al (1983) seemed effective in clearing secretions from distal airways. However, the apparatus used was apparently designed and manufactured specifically for their research. The results of these studies and the present study suggest that mechanical vi- brators generating frequencies of $8-15 \mathrm{~Hz}$ should be made more accessible.

In the group where the ventilation studies were done before the first and two hours after the second treatment, the failure of the ore patient, who produced a large amount of sputum, to show improvement can possibly be attributed to the time of the study. George et al (1985) recorded the best mucocilliary clearance at three to four and a half hours and this study was done six and a half hours after the first and two hours after the second treatment.

\section{CONCLUSION}

From this study, the following conclusion can be drawn: Mechanical vibration at $42 \mathrm{~Hz}$ does not mobilise secretions in peripheral airways and therefore atelectasis and gaseous exchange do not improve and can even deteriorate. It appears, however, that central secretions are mobilised by mecharical vibration and the airflow in the larger airways therefore improves.

\section{ACKNOWLEDGEMENTS}

I should like to thank the following people for their help and encouragement in the research project: Ms SH Irwin-Carruthers, Head of the Department of Physiotherapy, University of Stellenbosch, Dr JG van Wyk Kotze, Chief Specialist Scientist, Medical Research Council (MRC), and Ms SA Swanevelder, Assistant Biometrician, MRC.

\section{REFERENCES}

1. Anthonisen $P$, Riis $P$, Sogaard-Andersen $T$. The value of lung physiotherapy in the treatment of acute exacerbations in chronic bronchitis. Acta Med Scand 1964;175:715-9.

2. Buscaglia AJ, St Marie. Oxygen saturation during chest physiotherapy for acute exacerbations of severe COPD. Respir Care 1983;28:1009-13.

3. Cambell AH, O'Connel JM, Wilson F. The effect of chest physiotherapy upon the FEV1 in chronic bronchitis. Med J Aust 1975;1:33-5.

4. Conners AF, Hammon WE, Martin RJ et al. Chest physical therapy. The immediate effect on oxygenation in acutely ill patients. Chest 1980;78:559-64.

5. Craven KD, Oppenheimer L, Wood LDH. Effects of contusion and flail chest on pulmonary perfusion and oxygen exchange. J Appl Physiol 1979;47:729-37.

6. Feldman J, Traver GA, Taussig LM. Maximal expiratory flows after postural drainage. Am Rev Respir Dis 1979;119:239-45.

7. George RJD, Johnson MA, Pavio D et al. Increase in mucocilliary clearance in normal man induced by oral high frequency oscillation. Thorax 1985;40:433-7.

8. Greenspan L, McLellan BA, Greig H. Abbreviated injury scale and injury severity score: A scoring chart. J of Trauma 1985;25:60-4.

9. Holody B, Goldberg HS. The effect of mechanical vibration physiotherapy on arterial oxygenation in acutely ill patients with atelectasis or pneumonia. Am Rev Respir Dis 1980;124:372-5. 


\section{DEVELOPMENT OF A PRIVATE REHABILITATION UNIT - AN EXPERIENCE}

\section{Aphrodite Kastanos MSc \\ Physiotherapy \\ Diana Speer MCSP}

\section{INTRODUCTION}

Facilities available for specialised neurological and orthopaedic rehabilitation, based on the principle of a multidisciplinary approach, are very limited in South Africa. This type of specialised treatment has primarily been available at academic hospitals and those hospitals under the control of the mining industry. The resources available in these sectors have been put under enormous strain, thus limiting the quantity and quality of rehabilitation offered to the physically disabled.

\section{Barney Hurwitz Medical Institute}

In November 1991, the directors of a large group of hospitals agreed to convert an already existing hospital into a private rehabilitation institute that would cater for both in- and out-patients. A neurologist and therapists were involved in setting up the departments of physiotherapy, occupational therapy, speech therapy and social work. Nursing staff were responsible for setting up the wards for in-patients.

In February 1992, the establishment was opened, admitting post-acute neurologically impaired and poly-trauma

\section{continued from page 42}

10. Kigin CM. Chest physical therapy for the acutely ill medical patient. Phys Ther 1981;61:1724-36.

11. King M, Phillips DM, Gross Det al. Enhanced tracheal mucus clearance with high frequency chest wall compression. Am Rev Respir Dis 1983;128:511-5.

12. Mackenzie CF, Imle PC, Ciesla N. Chest Physiotherapy in the Intensive Care Unit. Second Edition. Baltimore, Hong Kong, London, Sydney: Williams \& Wilkins, 1989:6988,146-8,241.

13. Mackenzie CF, Shin B, McAslan TC. Chest physiotherapy: The effect on arterial oxygenation. Anesth Analg 1978;57:28-30.

14. Marini JJ, Pierson DJ, Hudson LD. Acute lobar atelectasis: a prospective comparison of fibreoptic bronchoscopy and respiratory therapy. Am Rev Respir Dis 1979;119:971-8.

15. Newton DA, Stephenson A. Effect of physiotherapy on pulmonary function. A laboratory study. Lancet 1978;2:228-9,

16. Pavia D, Thompson ML, Philliparos D. A preliminary study of the effect of a vibramat pad on bronchial clearance. Am Rev Respir Dis 1976;113:92-96.

17. Van Eeden SF. Notes on chest injuries for Intensive Care student nurses (in Afrikaans) 1990, University of Stellenbosch.

18. Wollmer P, Ursing K, Midgren B et al. Inefficiency of chest percussion in the physical therapy of chronic bronchitis. Eur J Respir Dis 1985;66:233-9. patients for intensive rehabilitation. Within six weeks it was recognised that the staff establishment needed to be expanded. By the end of May 1992, allied medical staff complement consisted of 2.5 physiotherapists, one occupational therapist, one social worker, 0.5 speech therapist, under a rehabilitation coordinator. A clinical psychologist was available on referral.

On admission to the institute, patients were assessed by each speciality, after which the therapists would confer and contract with the patient/caregiver. This allowed the patient and therapist a specific time to reach predetermined goals, as well as preparing the home environment for discharge of the patient.

The patients day was structured so that he was involved in a full day therapy programme with therapeutic activities being carried over in the ward. The programme also included a day or weekends at home prior to discharge from the ward whereafter outpatient therapy could continue. In addition full day, half day or sessional programmes were available to out-patients.

Liaison between disciplines included weekly ward meetings involving medical, nursing andallied medical staff as well as a weekly outpatient meeting.

\section{Problems}

\section{Financial}

Although the hospital charged medical aid tariffs, a significant number of patients' medical aids had reached the limit of benefits while the patient was still in an acute care hospital.

Representative Association of Medical Schemes (RAMS) refused to pay for services rendered by the therapists in the employ of the hospital.

Government gazetted codes as set out by RAMS for physiotherapy do not include a tariff for patients receiving extended periods of rehabilitation, or for assistants carrying out supervised exercise programmes.

Staff

The hospital required specialists in fields of physiotherapy, occupational therapy, speech therapy, social work and nursing. such specialists are scarce and required appropriate remuneration.

Legislation did not allow physiotherapists to be employed by any organisation/person other than the state, the mines of an independent physiotherapist.

\section{Discussion}

The establishment of a private rehabilitation institute in South Africa is an innovative and exciting concept. However, our medical resources do not provide for the comprehensive treatment and reintegration of the neurologically impaired individual into society. In many cases, by the time the patients were medically stable and ready for rehabilitation, they had reached the limit of their medical aid benefits and thus could not afford further treatment. This resulted in patients being discharged before reaching their maximal functional potential. Going home still functionally dependent to a unprepared environment puts considerable emotional and financial strain on family and caregivers.

Large institutions running on business principles cannot provide this type of service without showing a profit. Specialised therapists providing a professional service need to be suitably remunerated. Thus a balance must be found between the needs of society and the financial practicalities of running a private rehabilitation institute.

The cost of setting up a rehabilitation centre is substantial. Therefore, the benefits to the patient and community need to be critically appraised. Literature has indicated that rehabilitation in diagnostic groups is of maximal benefit predominantly due to the uniform approach to management (Flicker, 1989). This team approach should engender high moral, amongst the members and initiate research which acts as a catalyst to improve patient care and standards of treatment.

Literature indicates patients rehabilitated on stroke units / wards leave hospital sooner than those on general medical wards (Millikan, 1979). This implies that hospital costs per patient may be less on a stroke unit (Stevens et al, 1984). Results indicate a higher proportion of patients discharged from stroke units were independent compared with those from general medical units (Garraway et al 1980). Garraway found the mean length of stay in the stroke unit was 55 days in comparison to 75 days in a general medical ward. However, at one year follow-up the stroke unit benefit was no longer evident. Ongoing community follow-up is more likely to be utilised by those patients who received rehabilitation in a stroke unit (eg district nurses, physiotherapists and day centres) (Garraway et al 1981).

Studies comparing formalised neurorehabilitation with non-formalised treatment in functional and cognitive skills have been undertaken. Results show those patients who took part in the formalised programme gained a greater functional capacity with implications for return to work and decreased cost to, society (Mackay). There is now clear evidence as to the benefit to patients and cost effectiveness of skilled and appropriately delivered neurorehabilitation (Brooks, 1991). 